\title{
Regulative Development in a Spiralian Embryo as Shown by Cell Deletion Experiments on the Acoel, Childia ${ }^{1}$
}

\author{
BARBARA CONTA BOYER 2 \\ Department of Zoology, The University of Michigan, Ann Arbor, Michigan
}

\begin{abstract}
Spiral cleavage and mosaicism are closely associated in the Annelida, Mollusca, and probably the polyclad Turbellaria, but the evolutionary history of these phenomena remains uncertain. The Acoela, the most primitive order of turbellarians, exhibit spiral cleavage but with the formation of duets of micromeres rather than the more typical quartets. The regulative versus mosaic capacities of the acoel, Childia groenlandica, were investigated by deleting various combinations of blastomeres from the two-cell stage through the third duet. The acoel embryo showed extensive regulative ability since all experiments yielded normal animals except those in which both macromeres were deleted. These abnormal animals were ciliated spheres with a central cavity and indicated that the macromeres are necessary for form and organ differentiation. An inductive interaction between the micromeres and macromeres is suggested. Since mosaicism is probably specialized and a derivative of the indeterminate type of development, the regulative capacity of the acoel embryo suggests that this order lies near the ancestral line of the spiralia and represents an evolutionary stage where the very defined pattern of spiral cleavage is not yet associated with early programming of the cell's fate.
\end{abstract}

Since the turn of the century radial or unorganized cleavage has suggested regulation while spiral cleavage has been linked with mosaicism. Regulative development is characterized by the occurrence of cell interactions during early cleavage stages and partial embryos may develop into whole animals. In the classic cases of mosaic development, on the other hand, each blastomere as it forms has only the self-differentiative capacity to give rise to a particular larval structure and partial embryos therefore will develop into deficient animals. (It should be noted that recent investigations by Clement ('52, '62) and Cather ('67) have shown that the concept of strict mosaicism is, at least in some cases, an oversimplification.) Spiral cleavage occurs in the turbellarian flatworms, nemertines, annelids, molluscs, some crustaceans, and a few small phyla, though in its most characteristic form is found only in polyclad turbellarians, nemertines, annelids and molluscs.

The evolutionary relationships among the various spiralian groups and the association between spiral cleavage and mosaicism have been established and verified many times within the past century. The studies of Wilson (1892) on the polychaete Nereis and Conklin (1897) on the gastropod Crepidula showed that these spiralian embryos, representing two different phyla, cleaved in essentially the same manner and that their cell lineages were almost identical, establishing beyond question a close phylogenetic relationship between annelids and molluscs. Experiments soon followed which proved the mosaic nature of the spiralian embryo. In separating the blastomeres of the annelids Lanice (Wilson, '04a) and Chaetopterus (Tyler, '30) at the two-cell stage, Wilson and Tyler found that neither half was able to form a complete trochophore larva. Similar experiments on Sabellaria (Hatt, '32; Novikoff, '38a,b) and Tubifex (Penners, '26) indicated a high degree of mosaicism in the annelid embryo. In the most com-

1 This paper was part of a dissertation presented for the degree of Doctor of Philosophy in The University of Michigan.

2 Present address: Department of Biology, Whitman Laboratory, The University of Chicago, Chicago, Illinois. 
plete investigation of this type done on an annelid, Costello ("45) isolated the blastomeres of Nereis from the two-cell through the 32-cell stages and found that each blastomere cleaved and differentiated as if it were still in the embryo, concluding that the Nereis embryo is strictly mosaic with no interactions occurring between cells.

The mosaic character of the molluscan embryo was established by Wilson ('04b) working on the scaphopod Dentalium and the gastropod Patella and by Conklin (12) in a further study of Crepidula. Recently the early work has been extended and modified in a series of excellent papers by Clement ('52, '56, '62, '67) on the gastropod Ilyanassa.

The studies of Wilson (1898), Surface ('07) and Kato ('40) showed that polyclad Turbellaria cleave with almost exactly the same spiral pattern as annelids and molluscs, indicating a close phylogenetic relationship among these groups. Unfortunately no experimental work was done to determine the mosaic capacity of the polyclad embryo.

Except for the brief analyses of Costello ('37, '48) and a few European investigators, acoel turbellarian development has been neglected since 1909 when Bresslau published his study of the development of Convoluta roscoffensis. This work is preceded by only three investigations of any significance: the research of Pereyaslawzew $(1885,1893)$ on a number of acoel species, Gardiner (1895) on Polychoerus caudatus, and Georgévitch (1889) also on Convoluta roscoffensis. All indicated in their illustrations that early cleavage in acoels is spiral but only Bresslau recognized the relationship between the acoel cleavage pattern in which duets of micromeres are formed (figs. 1-6) and the more typical spiral pattern of polyclads, annelids and molluscs which form quartets of micromeres. His detailed comparison of acoel and polyclad cleavage indicated a close evolutionary affinity between these two turbellarian orders and thereby linked the acoels with the rest of the spiralia. None of these studies included an experimental analysis of acoel development.
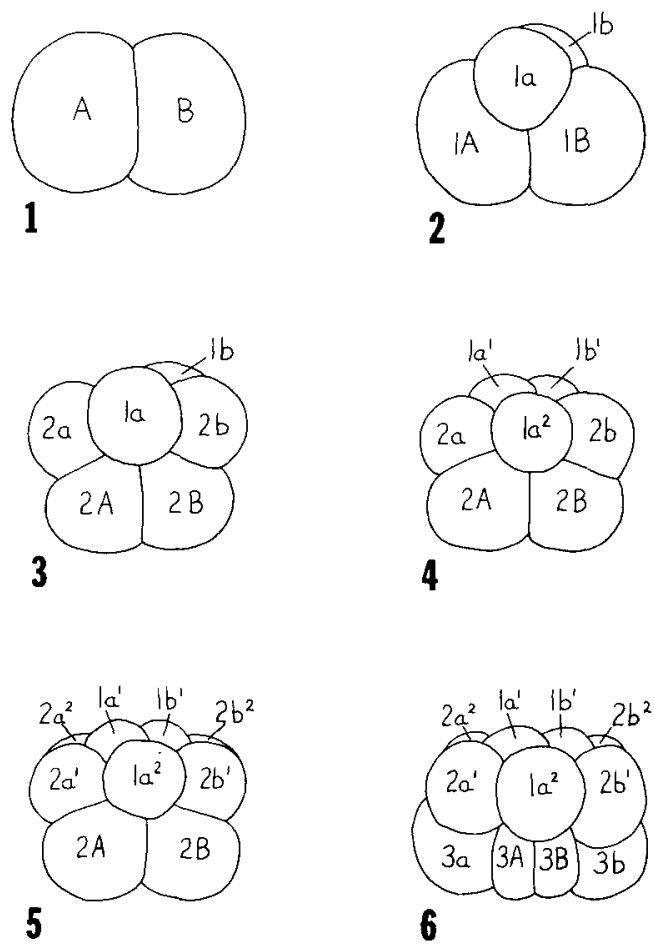

Figs. 1-6 Early cleavage in Childia groenlandica.

Fig. 1 Two-cell stage.

Fig. 2 Formation of the first duet of micromeres, $1 \mathrm{a}$ and $1 \mathrm{~b}$, from the $1 \mathrm{~A}$ and $1 \mathrm{~B}$ macromeres.

Fig. 3 Formation of the second duet of micromeres, $2 \mathrm{a}$ and $2 \mathrm{~b}$, from the $2 \mathrm{~A}$ and $2 \mathrm{~B}$ macromeres.

Fig. 4 Division of the first duet.

Fig. 5 Division of the second duet.

Fig. 6 Formation of the third duet of micromeres, $3 a$ and $3 \mathrm{~b}$, from the $3 \mathrm{~A}$ and $3 \mathrm{~B}$ macromeres.

Spiral cleavage and mosaicism seem to go hand-in-hand. But whether these phenomena evolved together or one preceded the other is not known. The acoels, the most primitive turbellarians have been shown to be definitively spiralian and the question arises: to what extent are they mosaic or regulative? With this question in mind, I undertook an investigation of the acoel embryo using cell deletion techniques similar to those used on other spiralian forms.

\section{METHODS}

The experiments were done at the Marine Biological Laboratory, Woods 
Hole on an acoel turbellarian which Costello and Henley refer to as Childia groenlandica (Henley, '68; Costello, Henley and Ault, '69) but which Bush (manuscript in preparation) believes to be an undescribed species of Childia. Animals, which occur abundantly on extensive intertidal beaches and mudflats at Dennis and Barnstable Harbor, Mass., were collected, maintained in finger bowls on the sea table and fed Artemia. Under these conditions eggs in transparent gelatinous masses were spawned regularly for about a week. The eggs, each surrounded by a tough capsule, were teased from the mass with tungsten needles. Attempts to remove the capsule chemically failed.

Cell deletions were performed through the intact egg capsule with sharp tungsten needles during the first several cleavage stages. Unless the injured cell cytolyzed completely with the first puncture it almost always healed after extruding some cytoplasm. Although this resiliency of the blastomeres was occasionally useful in deleting parts of cells, the most satisfactory method of operation was to cytolyze the cell completely with one puncture. Whole eggs from the same mass served as controls. The deletions were done in pasteurized sea water, the embryos were then transferred to penicillin-streptomycin sea water in $35 \mathrm{ml}$ stender dishes and put in a moist chamber after they were checked to see that the deletions were successful. The experimental embryos were observed periodically until two or three days after hatching when they were fixed in $3 \%$ glutaraldehyde in sea water for whole mount preparations or sectioning. The experimental series included deletion of one cell at the two-cell stage, deletion of micromeres singly or together, and one or both macromeres after the formation of each duet of micromeres; and excision of approximately half the embryo at later stages of development.

To prepare sections, embryos fixed in glutaraldehyde were dehydrated, embedbed in Epon, sectioned at two $\mu$, and stained with $1 \%$ toluidine blue and pyronin for 15-20 minutes.

\section{RESULTS}

The results consist of observations on living experimental embryos and analysis of sectioned hatchlings. Since even the adult acoel shows little differentiation at the organ level it is difficult to determine the effects of cell deletion on the whole animal. In observations of the living organism, therefore, a number of features were noted as criteria of differentiation. These included: (1) presence or absence of a mouth, (2) presence or absence of a statocyst, (3) distribution of pigment, (4) body shape, (5) ciliary versus muscular movement (a normal animal exhibits both while an abnormal one may lose muscular movement) and (6) behavior pattern. All experimental animals were classified according to these criteria. A section of a normal hatchling is seen in figure 7 , and figure 8 shows a Nomarski photomicrograph of a whole mount hatchling.

During the early stages of the investigation some difficulties were encountered in experimental techniques which were subsequently overcome with increased skill and the use of penicillin and streptomycin in the sea water. Consequently in some cases only the later results are presented although the previous work in no way contradicts these data.

The majority of the experiments produced normal though small animals. Therefore only a representative example of these results is presented along with all cases in which most animals were abnormal.

\section{Deletion of one cell at the two-cell stage-table 1}

All animals were half the size of the controls and only body shape and behavior were affected by the deletion.

TABLE 1

Deletion of one cell at the two-cell stage

\begin{tabular}{lcc}
\hline & Normal & Abnormal \\
\hline Mouth & 18 & 0 \\
Statocyst & 18 & 0 \\
Pigment & 18 & 0 \\
Body shape & 11 & 7 \\
Musc. movement & 18 & 0 \\
Behavior & 13 & 5 \\
\hline
\end{tabular}


Four of the five animals which showed abnormal behavior were also abnormal in body shape. The body shapes were highly variable ranging from ciliated spheres to abnormally long, thin worms. However most often the animals were only slightly contorted. Abnormal behavior almost always means that the animal circled rapidly, predominantly in one direction although most were observed to circle in both directions. The pattern varied from uninterrupted to occasional circling interspersed with normal swimming.

After the deleted cell had completely cytolyzed, continued cleavage of the remaining blastomere was observed in a number of embryos. In all cases not only did the remaining half cleave as if the embryo were whole, but at approximately the same rate as the controls.

Several experimental embryos were sectioned and except for size were indistinguishable from the controls.

Similar results were obtained in the following experiments with behavior and body shape being the only characteristics notably affected: (1) deletion of one cell of the first duet, (2) deletion of the first duet, (3) deletion of one macromere at the first duet, (4) deletion of one cell of the second duet, (5) deletion of the second duet, (6) deletion of one macromere at the second duet, (7) deletion of the third duet, and (8) deletion of one macromere at the third duet. Approximately $23 \%$ of the total number of animals operated on in these experiments showed any abnormalities. Of the $35 \mathrm{ab}$ normal animals, 11 or $31 \%$ were abnormal with respect to both body shape and behavior. When sectioned, representative animals from all of these experiments could not be distinguished from the controls.

\section{Deletion of both macromeres at the} first duet $(-1 A$ and $1 B)$-table 2

Considerable difficulty was encountered with this experiment and only four embryos survived to hatching. All embryos were little more than very small ciliated balls of cells, lacking mouth and statocyst and swimming by ciliary action only, thus affecting behavior as well. In all the pigment was unevenly dis- tributed into dark spots and almost transparent areas.

\section{Deletion of both macromeres at the} second duet $(-2 A$ and $2 B)$-table 2

The normal column represents one animal which was normal in all criteria. All abnormal animals were characterized by a round shape, no mouth or statocyst, concentrated spots of pigment with light areas between, and ciliary movement only.

Several experimental animals were sectioned and revealed cytological abnormalities (fig. 9). Most striking is the large cavity which always occurred in the center of the embryos. Though some embryos showed slightly more differentiation than others, all had relatively few nuclei and little epidermal or muscle differentiation. There was a large proliferation of metachromatic structures, probably gland cells, which penetrated to the exterior, and some differentiation of the peripheral and central parenchyma, with considerable vacuolization in the former. The central parenchyma in some animals appeared to be almost solid while in others the more typical meshwork containing lipid drops and concentrations of yolk was seen.

\section{Deletion of both macromeres at the third duet $(-3 A$ and $3 B)$-table 2}

The abnormal hatchlings looked very much like those obtained when $2 \mathrm{~A}$ and 2B were deleted though slightly larger. They were characteristically ciliated spherical embryos with no mouth or statocyst, irregular pigmentation, and swam by ciliary action only, resulting in continual spinning (fig. 10). Three hatchlings were almost normal though their bodies were irregular and they circled. One seemed to be completely normal.

In a few cases one macromere plus part of the second were deleted at the third duet. All resulting hatchlings were normal.

Sectioned hatchlings looked very similar to those in which $2 \mathrm{~A}$ and $2 \mathrm{~B}$ were deleted although somewhat more differentiated (fig. 11). The characteristic large cavity in the center of the embryo was always seen. The epidermis was indistinguishable from that of the control 
TABLE 2

Deletion of both macromeres after formation of the first duet of micromeres ( $-1 A$ and $1 B)$, after formation of the second duet $(-2 A$ and $2 B)$, and after formation. of the third duet $(-3 A$ and $3 B)$

\begin{tabular}{|c|c|c|c|c|c|c|}
\hline & \multicolumn{3}{|c|}{ Normal } & \multicolumn{3}{|c|}{ Abnormal } \\
\hline & $-1 \mathrm{~A}$ and $1 \mathrm{~B}$ & $-2 \mathrm{~A}$ and $2 \mathrm{~B}$ & $-3 \mathrm{~A}$ and $3 \mathrm{~B}$ & $-1 \mathrm{~A}$ and $1 \mathrm{~B}$ & $-2 \mathrm{~A}$ and $2 \mathrm{~B}$ & $-3 \mathrm{~A}$ and $3 \mathrm{~B}$ \\
\hline Mouth & 0 & 1 & 4 & 4 & 14 & 33 \\
\hline Statocyst & 0 & 1 & 4 & 4 & 14 & 33 \\
\hline Pigment & 0 & 1 & 4 & 4 & 14 & 33 \\
\hline Body shape & 0 & 1 & 1 & 4 & 14 & 36 \\
\hline Musc. movement & 0 & 1 & 4 & 4 & 14 & 33 \\
\hline Behavior & 0 & 1 & 1 & 4 & 14 & 36 \\
\hline
\end{tabular}

worms; a few gland canals opened to the exterior and a thin muscle layer was present internal to the epidermis. A larger number of nuclei were seen in these animals than in the previous experiment and the central and peripheral parenchymas were clearly distinct and quite well developed. Beneath the epidermal and muscle layers was the characteristic layer of peripheral parenchyma vacuoles and glands. The central parenchyma comprised the typical loose mesh interspersed with lipid drops and yolk. In some animals the central parenchyma seemed to be more complex than in the controls, containing a number of unidentifiable elements not seen in normal animals.

\section{Deletion of one-half the embryo at later stages - table 3}

To examine the degree of determination at later stages of development, approximately half the cells were excised from animals one to two days old (late gastrula). Table 3 shows that the majority of the animals were normal; they looked just like the controls except for their small size. All of the abnormal animals were ciliated spherical embryos indistinguishable superfically from embryos

TABLE 3

Deletion of one-half the embryo at later stages

\begin{tabular}{lcc}
\hline & Normal & Abnormal \\
\hline Mouth & 26 & 7 \\
Statocyst & 26 & 7 \\
Pigment & 26 & 7 \\
Body shape & 27 & 6 \\
Musc. movement & 27 & 6 \\
Behavior & 26 & 7 \\
\hline
\end{tabular}

in which the macromeres had been deleted although one did show some muscular movement and another had a tail. In section the abnormal embryos did not have a central cavity and were well differentiated at the tissue level.

\section{DISCUSSION}

All specific cell deletion experiments fall into two clearly discernible categories: (1) those in which the large majority of animals obtained after deletion were normal and including all experiments in which any combination of micromeres or just one macromere were deleted, and (2) those in which the large majority were aberrant, comprising only those experiments in which both macromeres were deleted. In any series there are a few exceptional cases-a common result in experiments of this kind-and the best explanation is that the exceptions in the first category are due to excessive surgical trauma and those of the second are due to incomplete deletion. It should be noted that the occurrence of abnormal behavior is often found in association with abnormal body shape. It seems probable therefore that in some cases circling may be caused by abnormal body shape, a characteristic which seems to be particularly sensitive to the deletion technique and perhaps is caused by improper growth of the ectoderm over the wound or by abnormal gastrulation.

of greatest significance are the results of deletion of one cell at the two-cell stage since this is the classic experiment in determining the regulative or mosaic capacities of an embryo. As shown in table 1 this deletion in Childia 
yields 56\% normal animals and proves that this embryo is able to regulate very well. The experiments involving combinations of micromere deletions indicate a regulative ability of the Childia embryo at least through formation of the third duet.

Deletion of both macromeres after formation of the first, second, and third duets (table 2) produces extremely abnormal hatchlings. They are always ciliated spheres with no mouth or statocyst and swim by ciliary action only. Embryos from which the first duet macromeres were deleted show high mortality. That the macromeres are needed at the four-cell stage for normal development is not particularly surprising since their deletion represents a very large protoplasmic loss for the embryo.

Although the hatchlings are superficially indistinguishable (except for size) when both macromeres are killed at the second and third duets, sections reveal some difference in amount of differentiation. Deletion of $2 \mathrm{~A}$ and $2 \mathrm{~B}$ resulted in poor epidermal and muscle development, few nuclei, and a preponderance of gland cells. In contrast, deletion of $3 \mathrm{~A}$ and $3 \mathrm{~B}$ produced animals which were well differentiated at the tissue level and were often identical with the controls in this respect. Both types of experiments were always characterized by a large cavity in the center of the hatchling.

A number of conclusions can be drawn from these results. The central cavity is probably the consequence of abnormal gastrulation in the absence of the macromeres. Without the macromeres invagination is impossible but cell division and epiboly proceed and cover the blastopore as in the normal embryo, leaving a cavity where the macromeres would be after normal gastrulation.

While the extreme abncrmalities after deletion of $1 \mathrm{~A}$ and $1 \mathrm{~B}$ might be simply the result of insufficient protoplasm to support normal development, this cannot be the explanation for the results of deleting $3 \mathrm{~A}$ and $3 \mathrm{~B}$. This experiment produces considerably less protoplasmic loss than deletion of one cell at the twocell stage yet the latter yields normal worms. Total loss of protoplasm after deletion of $2 \mathrm{~A}$ and $2 \mathrm{~B}$ is probably no greater than when one cell is removed at the two-cell stage and therefore in itself would not be the cause of abnormality in this case either. However the internal differences seen between hatchlings after deletion of the second versus third duet macromeres may be attributable to the smaller mass of the former.

The data suggest some specific functions of the macromeres in development. It has been shown that no single duet of micromeres is necessary for normal development. However the first three duets alone form an abnormal embryo but one in which differentiation at the tissue level is normal and complete. In other words the micromeres are able to self-differentiate to form the epidermis and peripheral and central parenchymas, but for differentiation of form (body shape) and organs such as the statocyst and mouth the macromeres are necessary, suggesting an inductive interaction between the micromeres and macromeres. Deletion of one macromere plus part of another results in the formation of a normal embryo, indicating that only a small amount of macromere material is necessary for normal development. A parallel situation occurs in the mosaic embryo of Ilyanassa for which Cather ('67) has shown that an interaction between the first three quartets of micromeres and some macromere material is necessary for the formation of shell. Attempts to test the developmental capacity of the macromeres in isolation failed.

Fig. 7 Section of a normal hatchling. Epidermis (E), Peripheral Parenchyma (PP), Central Parenchyma (CP), Statocyst (S), Vacuole (V). About $\times 450$.

Fig. 8 Nomarski photomicrograph of a whole mount hatchling. About $\times 250$.

Fig. 9 Section of a hatchling from which both macromeres were deleted at the second duet ( $-2 \mathrm{~A}$ and 2B). Epidermis (E), Peripheral Parenchyma (PP), Central Parenchyma (CP), Cavity (C), Gland (G). About $\times 350$.

Fig. 10 Nomarski photomicrograph of a whole mount hatchling from which both macromeres were deleted at the third duet $(-3 \mathrm{~A}$ and 3B). About $\times 300$.

Fig. 11 Section of a hatchling from which both macromeres were deleted at the third duet $(-3 \mathrm{~A}$ and $3 \mathrm{~B})$. Epidermis (E), Peripheral Parenchyma (PP), Central Parenchyma (CP), Cavity (C). About $\times 350$. 

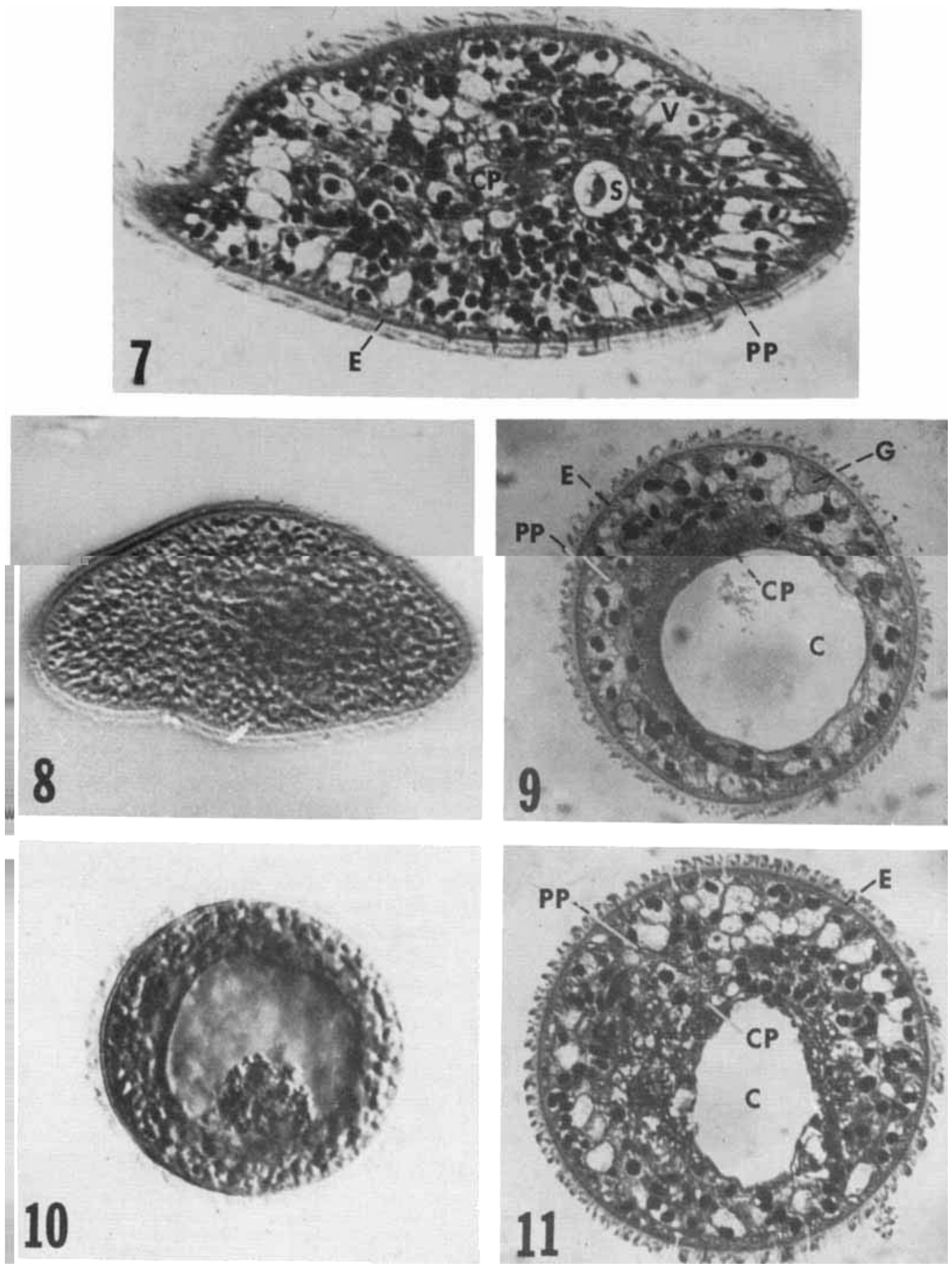

Figures 7-11 
As indicated in table 3 , two kinds of animals result from experiments in which about half the embryo was excised between one and two days of development and fall into either category 1 as normal hatchlings or category 2 as ciliated spheres. The normal animals provide evidence that even after the completion of cleavage and the beginning of differentiation the embryo is able to regulate to form a whole individual. The morphology of the ciliated spheres suggests that the macromere derivatives had been deleted from these embryos and therefore that the macromere-micromere interactions which appear to be necessary for normal development occur after the completion of cleavage and involve a number of small cells rather than the intact macromeres. These abnormal embryos, which gastrulated before the deletion was performed, do not have a central cavity and support the hypothesis that the presence of a cavity in the macromere-deleted hatchlings results from abnormal gastrulation.

The specific implications of the experiments have been examined; what can these data now tell us about spiral cleavage and mosaicism? It is generally accepted that the acoel Turbellaria are the most primitive flatworms (Hyman, '51; Hadzi, '63; Hanson, '63), an hypothesis well supported by anatomical and morphological studies. The Acoela are primitive in every system except the reproductive system which has attained complexity in some forms but which nonetheless lacks definitive gonads and oviducts. If the Acoela were degenerate one would expect to find them in relatively specialized, quite uniform environments (living perhaps as endoparasites); on the contrary we find the group wide-ranging and free-living in a variety of habitats.

Acoel embryology also suggests that this group may represent the most primitive spiralian. Although the acoel pattern of spiral cleavage is quite defined, a characteristic of all mosaic forms, it is obvious even without experimental verification that the degree of cell determination is not as highly specific as in the annelids and molluscs. Most notably in acoels there is no cell corresponding to
$4 \mathrm{~d}$ which gives rise to all of the mesoderm and at least part of the endoderm in quartet forms. Instead the mesoderm and endoderm, which are not clearly defined in the Acoela, appear to originate from an inwandering of cells during gastrulation. Since one cannot destroy all of the mesoderm by deleting one cell, these animals have already proved to be less mosaic than groups possessing a $4 d$ cell. Deletion of one cell at the twocell stage invariably leads to partial larvae in all annelids and molluscs which have been tested, but the present study has shown that the same deletion in acoels gives rise to a normal though half-size worm. Micromere deletions also yield no abnormalities in acoels while similar experiments on quartet spiralians result in imperfect larvae. Thus, acoels regulate far better than annelids and molluscs. As Hyman ('51) states, "the determinative mode of development seems specialized and shortened from the indeterminate type." Therefore the capacity of the spiralian acoel embryo for regulation suggests that this order represents the stem group of the spiralia and indicates that spiral cleavage arose as the duet form in association with regulative development and only later in evolution became inseparable from mosaicism.

\section{ACKNOWLEDGMENTS}

I wish to thank Dr. James N. Cather for his help and encouragement throughout this investigation.

This work was supported by The National Institutes of Health Graduate Training grant, 5T01 GM00989.

\section{LITERATURE CITED}

Bresslau, E. 1909 Die Entwicklungen der Acoelen. Verhandl. Dtsch. Zool. Gesell., 19: 314-324.

Cather, J. N. 1967 Cellular interactions in the development of the shell gland of the gastropod, Ilyanassa. J. Exp. Zool., 166: 205-224.

Clement, A. C. 1952 Experimental studies on germinal localization in Ilyanassa. I. The role of the polar lobe in the determination of the cleavage pattern and its influence in later development. J. Exp. Zool., 121: 593-626.

1956 Experimental studies on germinal localization in Ilyanassa. II. The development of isolated blastomeres. J. Exp. Zool., 132: $427-446$. 
1962 Development of Ilyanassa following removal of the $D$ macromere at successive cleavage stages. J. Exp. Zool., 149: 193-216.

1967 The embryonic value of the $\mathrm{mi}$ cromeres in Ilyanassa obsoleta, as determined by deletion experiments. I. The first quartet cells. J. Exp. Zool., 166: 77-88.

Conklin, E. G. 1897 The embryology of Crepidula. J. Morph., 13: 1-226.

1912 Experimental studies on nuclear and cell division in the eggs of Crepidula. J. Acad. Nat. Sci. Phila., ser. 2, 15: 501-591.

Costello, D. P. 1937 The early cleavage of Polychoerus carmelensis. Anat. Rec., 70: Suppl. 1: 108-109.

1945 Experimental studies of germinal localization in Nereis. I. The development of isolated blastomeres. J. Exp. Zool., 100: 19-66. - 1948 Spiral cleavage. Biol. Bull., 95: 265.

Costello, D. P., C. Henley and C. R. Ault 1969 Microtubules in spermatozoa of Childia (Turbellaria, Acoela) revealed by negative staining. Science, 163: 678-679.

Gardiner, E. G. 1895 Early development of Polychoerus caudatus Mark. J. Morph., 11: 155-176.

Georgévitch, J. 1899 Étude sur le développement de la Convoluta roscoffensis Graff. Arch. Zool. Expérimen., ser. 3, 7: 343-361.

Hadzi, J. 1963 The Evolution of the Metazoa. Macmillan Co., New York.

Hanson, E. D. 1963 Homologies and the ciliate origin of the Eumetazoa. In: The Lower Metazoa. E. C. Dougherty, Z. N. Brown, E. D. Hanson and W. D. Hartman, eds. University of California Press, Berkeley and Los Angeles, pp. 7-22.

Henley, C. 1968 Refractile bodies in the developing and mature sperm of Childia groenlandica (Turbellaria: Acoela) and their possible significance. Biol. Bull., 134: 382-397.

Hatt, P. 1932 Essais expérimentaux sur les localizations germinales dans l'oeuf d'un Anné- lide (Sabellaria alveolata L.) Arch. d'Anat. Micros., 28: 81-98.

Hyman, L. H. 1951 The Invertebrates. Vol. II. McGraw-Hill, New York.

Kato, K. 1940 On the development of some Japanese polyclads. Japan. J. Zool., 8: 537573.

Novikoff, A. B. 1938a Embryonic determination in the annelid Sabellaria vulgaris. I. The differentiation of ectoderm and endoderm when separated through induced gastrulation. Biol. Bull., 74; 198-210.

1938b Embryonic determination in the annelid Sabellaria vulgaris. II. Transplantation of polar lobes and blastomeres as a test of their inducing capacities. Biol. Bull., 74: 211-234.

Penners, A. 1926 Experimentelle Untersuchungen zum Determinationsproblem am Keim von Tubifex rivulontm Lam. II. Die Entwicklung teilweise abgetöteter Keime. Zeit. Wiss. Zool., 127: 1-140.

Pereyaslawzew, S. 1885 Sur le développement des Turbellariés. Zool. Anzeiger, 8: 269-271.

- 1893 Monographie des Turbellariés de la mer Noire. Mem. Neo-Russian Soc. Natur., 17: 164-204.

Surface, F. M. 1907 The early development of a polyclad Planocera inquilina. Proc. Acad. Nat. Sci. Phila., 59: 514-559.

Tyler, A. 1930 Experimental production of double embryos in annelids and molluses. J. Exp. Zool., 57: 347-408.

Wilson, E. B, 1892 The cell-lineage of Nereis. J. Morph., 6: 361-480.

1898 Considerations on cell lineage and ancestral reminiscence, based on a reexamination of some points in the early development of annelids and polyclads. Ann. N. Y. Acad. Sci., 11: 1-27.

1904a Mosaic development in the annelid egg. Science, 20: 748-750.

$1904 \mathrm{~b}$ Experimental studies on germinal localization. II. Experiments on the cleavage mosaic in Patella and Dentalium. J. Exp. Zool., 1; 197-268.

Note added in proof: A recent paper (Apelt, G. 1969 Fortpflanzungsbiologie, Entwicklungszyklen und vergleichende Frühentwicklung acoeler Turbellarien. Marine Biol., $4: 267-325$ ) includes a comparative study of cleavage in a number of acoel species. 